\title{
Neoskrjabinolepis merkushevae sp. n. (Cyclophyllidea: Hymenolepididae), a new cestode from shrews from the Palaearctic region
}

\author{
Svetlana A. Kornienko ${ }^{1}$ and Rasa Binkiené ${ }^{2}$ \\ ${ }^{1}$ Institute of Systematics and Ecology of Animals, Siberian Branch, Russian Academy of Sciences, 11 Frunze Street, \\ 630091 Novosibirsk, Russia; \\ ${ }^{2}$ Institute of Ecology, Vilnius University, Akademijos 2, LT-08412 Vilnius-21, Lithuania
}

Key words: Cestoda, Hymenolepididae, Neoskrjabinolepis, Sorex, Palaearctic region

\begin{abstract}
Neoskrjabinolepis (Neoskrjabinolepidoides) merkushevae sp. $\mathrm{n}$. is described from the shrew Sorex minutus L. (type host) from Belarus. The new species is characterised by rostellar hooks 35-37 $\mu \mathrm{m}$ long, provided with small epiphyseal thickening of the handle; short $(35-40 \mu \mathrm{m})$ cirrus consisting of a basal part with claw-shaped spines, a parabasal part with thin needleshaped spines and an unarmed distal part; cirrus-sac slightly passing into median field; and 12-16 eggs per gravid uterus. In addition to the type host and the type locality, the host range of the new species includes Sorex araneus L. and there are geographical records from Bulgaria, Lithuania and North-East Altay (Russia).
\end{abstract}

Until now, only two species of the genus Neoskrjabinolepis Spassky, 1947 parasitizing shrews in Europe have been known, namely $N$. singularis (Cholodkowsky, 1912) Spassky, 1954 and N. schaldybini Spassky, 1947 (Spassky 1947, 1954, Arzamasov et al. 1969, Spassky and Andreyko 1970, Vaucher 1971, Merkusheva and Bobkova 1981, Genov 1984, Haukisalmi 1989, Binkienè 2006). However, six other species of the genus Neoskrjabinolepis from shrews have recently been described from the Asian part of Russia (Kornienko et al. 2006, 2007). At the same time, two groups of species differing by the type of their strobilar development were identified within the genus Neoskrjabinolepis and a distinct subgenus was erected for each of these groups. The species with gradual strobilation were retained in the nominate subgenus Neoskrjabinolepis Spassky, 1947. Species with serial strobilation were moved to the subgenus Neoskrjabinolepidoides Kornienko, Gulyaev et Melnikova, 2006 (Kornienko et al. 2006). The aim of the present study is to describe a new species of the subgenus Neoskrjabinolepidoides parasitizing shrews in Belarus, Bulgaria, Lithuania and NorthEast Altay (Russia).

\section{MATERIALS AND METHODS}

The cestodes studied are from the collection of I.V. Merkusheva stored at the Institute of Zoology in Minsk (Belarus) and the collection of T. Genov stored at the Central Laboratory of General Ecology, Bulgarian Academy of Sciences (Bulgaria). Additional material from shrews from Lithuania and from the South of the Western Siberia was collected by the present authors. Host specimens were dissected immediately after their death. Cestodes were isolated, washed and relaxed in water, and fixed in $70 \%$ ethanol. They were stained in Ehrlich's haematoxylin, differentiated in 3\% aqueous solution of ferric ammonium sulphate 12-hydrate, dehydrated in ethanol series, cleared in clove oil and mounted in Canada balsam. Some specimens were mounted in Berlese's medium to facilitate examination of rostellar hooks and copulatory apparatus.

Measurements are given in micrometres $(\mu \mathrm{m})$ except where otherwise stated; they are presented as the range followed by the mean and the number of the measurements (n) in parentheses.

Type specimens of the present species are deposited in the Natural History Museum, Geneva (MNHG), the collection of the Laboratory of Parasitology of the Institute of Ecology of Vilnius University, Lithuania (EKOI), the Museum of Zoology of the Institute of Systematics and Ecology of Animals, Novosibirsk, Russia (ISEA) and the Helminthological Collection, Institute of Parasitology, Biology Centre, Academy of Sciences of the Czech Republic, České Budějovice (IPCAS).

\section{RESULTS}

\section{Neoskrjabinolepis (Neoskrjabinolepidoides) merkushevae sp. $\mathrm{n}$. \\ Figs. 1-9}

Description (based on specimens from the type host): Gravid specimens $5.0-7.0 \mathrm{~mm}(6.3 \mathrm{~mm}, \mathrm{n}=10)$ long, with maximum width at level of postmature proglottides, 400-490 (467, $\mathrm{n}=8)$; strobila flat, consisting of 200-240 $(225, \mathrm{n}=10)$ proglottides. Strobilation serial: pregravid strobila usually consisting of four series of proglottides, each containing proglottides at same developmental stage (first series of juvenile or premature proglottides; second series of hermaphroditic mature proglottides; third series of postmature proglottides; fourth 

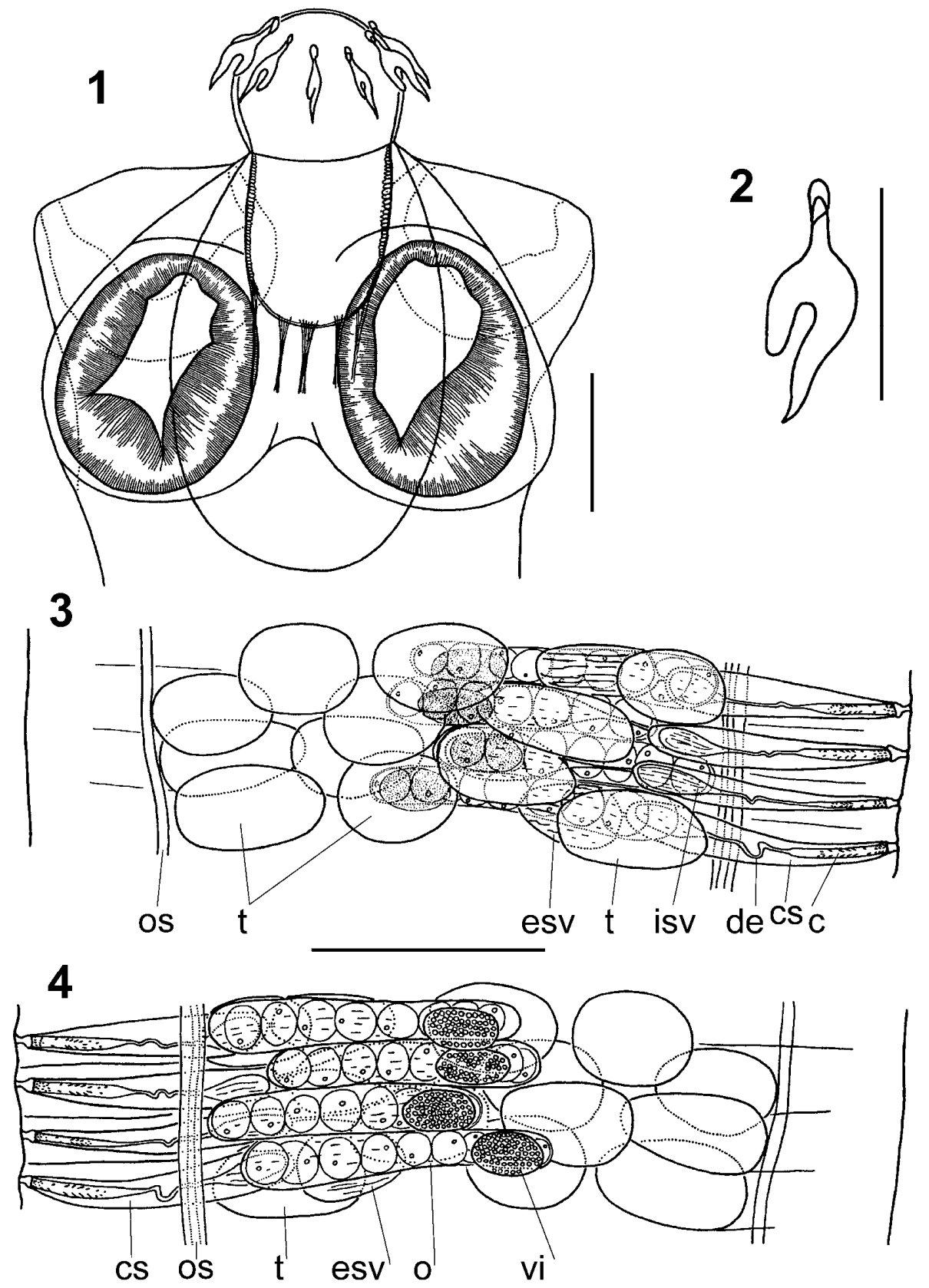

Figs. 1-4. Neoskrjabinolepis (Neoskrjabinolepidoides) merkushevae sp. n. Holotype, MHNG INVE 55311. Fig. 1. Scolex. Fig. 2. Rostellar hook. Fig. 3. Mature proglottides, dorsal view. Fig. 4. Mature proglottides, ventral view. Abbreviations: c - cirrus; cs - cirrus-sac; de - ductus ejaculatorius; esv - external seminal vesicle; isv - internal seminal vesicle; o - ovary; os - osmoregulatory canal; $\mathrm{t}$ - testis; vi - vitellarium. Scale bars: Figs. 1, 3, $4=50 \mu \mathrm{m}$; Fig. $2=30 \mu \mathrm{m}$.

series of pregravid or gravid proglottides); each series consisting of c. $48-60$ proglottides. Strobilar portions containing juvenile, premature or mature proglottides without external segmentation; proglottides externally distinct at level of postmature ones.

Scolex delineated from neck (Fig. 1), with maximum diameter 170-180 $(173, \mathrm{n}=9)$. Diameter of neck 150$160(157, \mathrm{n}=9)$. Suckers cup-shaped, 88-90 × 76-80 $(88 \times 78, \mathrm{n}=9)$, with well-developed musculature. Rostellar apparatus complex. Rhynchus short, 53-55 long and $65-67$ wide $(53 \times 65, \mathrm{n}=7)$. Rostellum sac-like, $110-120 \times 60-65(116 \times 62, \mathrm{n}=10)$, its wall consisting of external layer of longitudinal muscular fibres and internal layer of circular muscular bundles. Rostellar hooks 10 in number, arranged in single row, 35-37 (37, $\mathrm{n}=8$ ) long, with characteristic pincer-like shape: axis of blade almost parallel to axis of guard, blade twice longer than handle (Fig. 2); blade with characteristic bending in its middle part; guard lies close to blade; handle provided with small epiphyseal thickening. 
When rostellar apparatus retracted, rostellar hooks with blades directed anteriorly. Rostellar pouch voluminous, $160-200 \times 100-110(183 \times 106, \mathrm{n}=6)$, reaching beyond level of posterior margins of suckers; its wall consisting of longitudinal muscular fibres and circular muscular bundles.

Proglottides acraspedote, transversely elongate. Mature and pregravid proglottides much wider than long, 9-11 × 200-230 $(9 \times 215, \mathrm{n}=8)($ Figs. 3, 8) and 14-16 $\times 200-250(16 \times 235, \mathrm{n}=10)$, respectively. Lateral fields 34-35 $(34, \mathrm{n}=8)$ wide. Gravid proglottides slightly wider than long, e.g., 250-260 × 280-300 (254 $\times 287, \mathrm{n}=7$ ) (Fig. 9). Two pairs of osmoregulatory canals without transverse anastomoses, ventral canals 4.5$5(4.5, \mathrm{n}=6)$ wide, dorsal canals $1.5-2(1.7, \mathrm{n}=6)$ wide. Genital pores unilateral. Genital atrium simple, 2 2.5 deep, 3.6-4.0 in diameter.

Testes three, oval 17-24 × 28-39 $(21 \times 33, \mathrm{n}=8)$, situated in one row (two testes antiporal, one testis poral) (Fig. 3). Diameter of testes larger than proglottis length and, as result, dense dorsal testicular field formed in mature strobilar portion. Degenerating testes persisting in postmature proglottides. Cirrus-sac claviform, $60-65 \times 7-8(64 \times 7, \mathrm{n}=8)$, thin-walled, slightly crossing poral osmoregulatory canals (Fig. 6). Evaginated cirrus short, cylindrical, 35-40 $(35, \mathrm{n}=6)$; its basal part armed with small claw-shaped spines, middle part provided with sparse needle-shaped spines (Fig. 7). Length of needle-shaped spines decreasing distally. Distal end of cirrus unarmed. Ductus ejaculatorius slightly curving. Internal seminal vesicle small, 14-18 $\times 4-6(15 \times 4, \mathrm{n}=$ $6)$, occupying when filled less than $1 / 3$ of cirrus-sac length. Small external seminal vesicle, $25-34 \times 13-16$ $(30 \times 15, n=8)$, connected with cirrus-sac by short, thin duct.

Vitellarium subspherical, 14-22 × 9-14 $(19 \times 12, \mathrm{n}=$ $8)$, situated median and ventral to ovary. Ovary transversely elongate, compact, $77-83 \times 9-12(79 \times 10, \mathrm{n}=$ 8 ), allocated in poral part of median field ventral to cirrus-sac, external seminal vesicle and testes (Fig. 4); ovocytes large. Vagina thin-walled (Fig. 5). Its copulatory part, $33-37 \times 5-5.5(34 \times 5, \mathrm{n}=5)$, well delineated from conductive part. Vaginal pore posterior to pore of cirrus-sac. Seminal receptacle transversely elongate, $40-45 \times 4-6(42 \times 4, n=5)$.

Uterus not passing into lateral fields in both postmature and gravid proglottides (Figs. 8, 9). Uterine wall thin, membraneous during all morphogenesis of uterus. Number of eggs in uterus 12-16. Gravid eggs 33-40 $\times$ 23-29 $(35 \times 27, \mathrm{n}=10)$, embryophore $22-27 \times 18-23$ $(24-19, \mathrm{n}=10)$, oncosphere $21-25 \times 16-21(23-18, \mathrm{n}=$ 10). Embryonic hooks: lateral pair $9.6-10.5(10.1, \mathrm{n}=$ 7) long, medial pair 10.0-10.8 $(10.5, \mathrm{n}=7)$ long.

T y p e h o s t : Sorex minutus L., 1766 (Soricomorpha: Soricidae).

O t h e r h o s t: Sorex araneus L., 1758.
Ty p e lo c a lity: Vicinities of the village of Krestunov in Luninets District, Brest Region, Belarus $\left(52^{\circ} 17^{\prime} 75^{\prime \prime} \mathrm{N}\right.$, 2639'35'"E).

O the r lo c a lit i e s: Vicinities of the village of Kruglyany in Senno District, Vitebsk Region, Belarus (54 $\left.53^{\prime} 70^{\prime \prime} \mathrm{N}, 29^{\circ} 58^{\prime} 93^{\prime \prime} \mathrm{E}\right)$; Lithuania: vicinities of the village of Pūzraviečiai, Šilutè District $\left(55^{\circ} 28^{\prime} 24^{\prime} \mathrm{N}, 21^{\circ} 41^{\prime}\right.$ $28^{\prime \prime}$ ), vicinities of the village of Miliai, Moletai District $\left(55^{\circ} 14^{\prime} 59^{\prime \prime} \mathrm{N}, 25^{\circ} 36^{\prime} 18^{\prime \prime} \mathrm{E}\right)$, vicinities of the village of

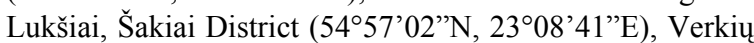
Park, Vilnius $\left(54^{\circ} 45^{\prime} 02^{\prime \prime} \mathrm{N}, 2^{\circ} 15^{\prime} 89^{\prime \prime} \mathrm{E}\right)$; Russia: surroundings of the village of Artybash, Altay Republic,

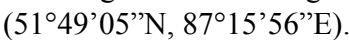

T y p e m a t e ri a 1: Holotype MHNG, INVE 55311, Belarus, 25.09.1965. Paratypes: EKO HELMI 321, Lithuania, Molètai District, 16.05.2002; HELMI 322-325, Lithuania, Šilutė District, 21.06.2001, 10.08.2000, 11.08.2001, 02.07.1999; ISEA 1647-1648, Russia, Altay Republic, 14.08.2004; IPCAS C-491, Lithuania, Šilutè District 21.06.2001.

$\mathrm{S}$ i t e : Intestine.

$\mathrm{P}$ r e v a 1 e $\mathrm{n}$ c e : $24.6 \%$ (14 of 57 S. minutus from Russia, Altay Republic), $54.9 \%$ (28 of 51 S. minutus from Lithuania) and $1.9 \%$ (3 of 154 S. araneus from Lithuania).

E t y m o 1 o g y : The specific name is dedicated to Dr. Iya Vasiljevna Merkusheva, in recognition of her contribution to helminthology.

\section{DISCUSSION}

Neoskrjabinolepis merkushevae is characterized by serial strobilar development. Therefore, it belongs to the subgenus Neoskrjabinolepidoides of Neoskrjabinolepis. At present, the subgenus Neoskrjabinolepidoides includes four species: N. singularis (Cholodkowsky, 1912) Spassky, 1954 from Sorex araneus, S. caecutiens Laxmann, S. isodon Turov, and S. minutus; N. nadtochijae Kornienko, Gulyaev et Melnikova, 2006 from $S$. caecutiens, S. isodon and S. unguiculatus Dobson; N. corticirrosus Kornienko, Gulyaev et Melnikova, 2007 from S. caecutiens, S. tundrensis Merriam and S. portenkoi Stroganov; N. kedrovensis Kornienko, Gulyaev et Melnikova, 2007 from S. unguiculatus, S. isodon and S. caecutiens. Key to the species of the subgenus Neoskrjabinolepidoides was given in another article by Kornienko et al. (2007). However, only $N$. singularis is known in Europe, whereas the other species are parasites of shrews in Asia. The new species is the smallest cestode among the species belonging to this subgenus.

Neoskrjabinolepis merkushevae differs from $N$. kedrovensis by the shape of rostellar hooks (guard slightly turned to the blade), the size of the cirrus-sac and the armament of the cirrus (see below). The length of hooks of the two species is similar (35-37 and 3638). The remaining species of this subgenus have longer hooks: N. singularis 56-65, N. nadtochijae 40-44 and N. corticirrosus 48-53. 

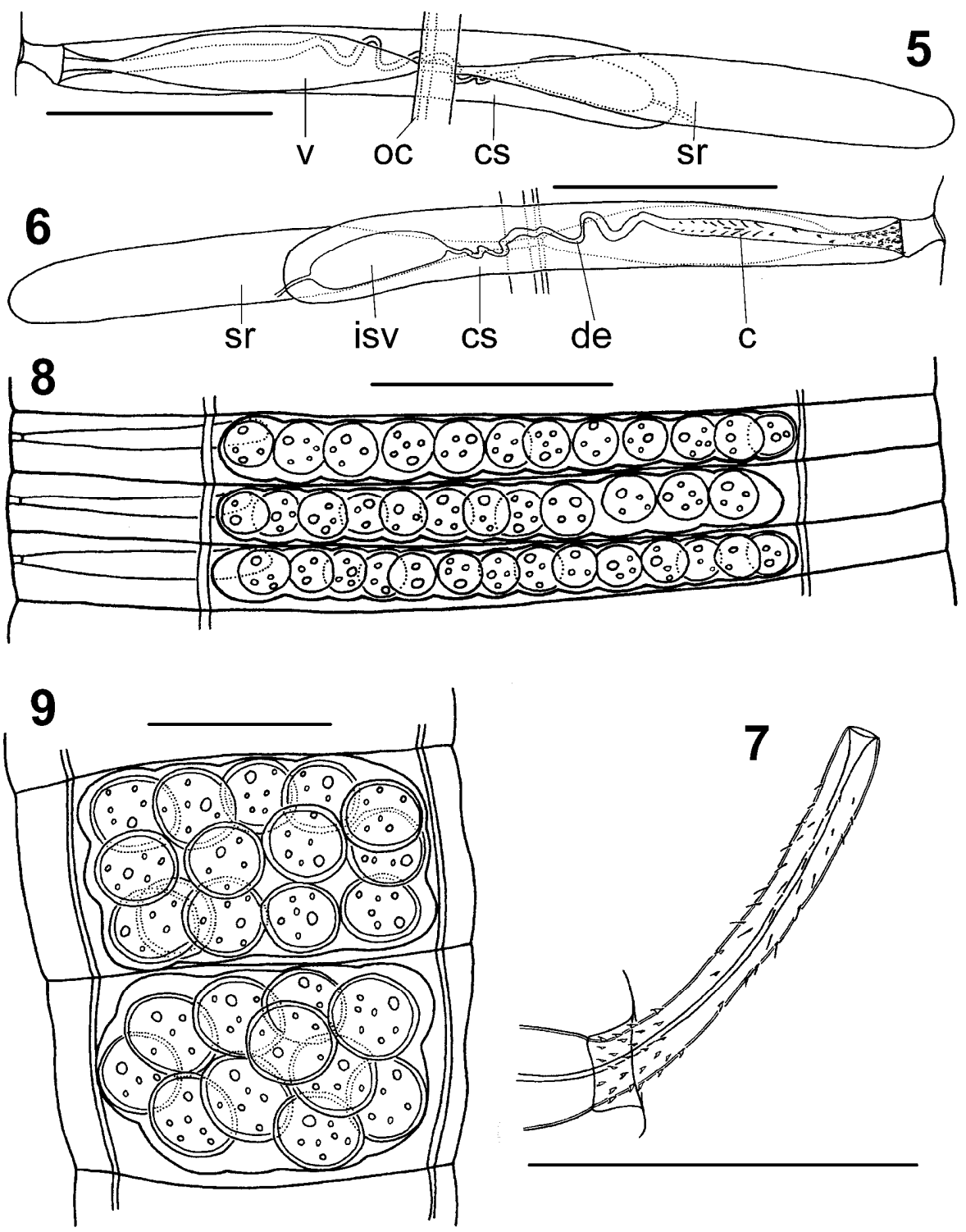

Figs. 5-9. Neoskrjabinolepis (Neoskrjabinolepidoides) merkushevae sp. n. Holotype, MHNG INVE 55311. Fig. 5. Vagina. Fig. 6. Cirrus-sac. Fig. 7. Cirrus. Fig. 8. Pregravid proglottides. Fig. 9. Gravid proglottides. Abbreviations: c - cirrus; cs - cirrussac; de - ductus ejaculatorius; isv - internal seminal vesicle; os - osmoregulatory canal; sr - seminal receptacle; $v$ - vagina. Scale bars: Figs. $5-7=30 \mu \mathrm{m}$; Figs. $8,9=50 \mu \mathrm{m}$.

Additionally, the new species has the shortest cirrussac and cirrus (60-65 and 35-40, respectively) and thus differs from $N$. nadtochijae and $N$. kedrovensis (cirrussac length 160-180 and 110-120, respectively). The measurements of the cirrus-sac and cirrus of $N$. corticirrosus (70-90 and 50-55) are close to those of $N$. merkushevae; however, these species could be distinguished from each other by the differences in armament of the cirrus. The middle part of the cirrus of $N$. merkushevae is armed with sparse needle-shaped spines and the distal part of cirrus is unarmed, whereas the distal part of the cirrus of $N$. corticirrosus is armed with relatively bigger needle-shaped spines. Moreover, these species differ by the number of eggs in gravid proglottides. The gravid uterus of $N$. merkushevae contains 12-16 eggs only, whereas that of $N$. corticirrosus 20 eggs and that of $N$. singularis 34-43.

Neoskrjabinolepis merkushevae and N. schaldybini Spassky, 1947 have rostellar hooks of similar size (3537 and 38-43, respectively). This was the reason why the previous authors (Arzamasov et al. 1969, Genov 1984, Binkiene 2006) did not distinguish these species and identified tapeworms now described as $N$. merkushevae as $N$. schaldybini. However, the present study shows that $N$. merkushevae differs from $N$. schaldybini by the pattern of strobilar development, the shape and length of the blade and also by measurements of the epiphyseal thickening of rostellar hooks. The blade of 
rostellar hooks of $N$. merkushevae is longer in relation to the guard than that of $N$. schaldybini. N. merkushevae has a characteristic curvature of the blade in its middle part, while the blade of $N$. schaldybini is almost straight. The epiphyseal thickening of rostellar hooks of the new species is much smaller than that of $N$. schaldybini.

Neoskrjabinolepis merkushevae could also be distinguished from $N$. schaldybini by the armament of the cirrus, despite their similar lengths (35-40 and 38-43, respectively). $N$. schaldybini has few large claw-shaped spines in the parabasal part of the cirrus, while the parabasal part of the cirrus of $N$. merkushevae is not armed with such spines. Moreover, the spines on the middle part of the cirrus of $N$. schaldybini are three to four times longer than those of the cirrus of $N$. merkushevae. The distal part of the cirrus of $N$. merkushevae is unarmed.

On the basis of the above comparisons, we recognise the material studied as a new species.

Acknowledgements. We are grateful to Drs. V.D. Gulyaev and J. Komisarovas for reading the manuscript and making useful suggestions. We also thank two anonymous reviewers for their very helpful comments. Substantial part of the work was funded by the Russian Fund of Fundamental Research (project No. 05-04-49010) and the Lithuanian State Science and Studies Foundation (project No. T-07071).

\section{REFERENCES}

ArZamasov I.T., Merkusheva I.V., MiholaP O.N., CHIKILEVSKAYA I.V. 1969: [Insectivora and their parasites in Belarus.] Nauka i tehnika, Minsk, 176 pp. (In Russian.)

BINKIENE R. 2006: Helminth fauna of shrews (Sorex spp.) in Lithuania. Acta Zool. Lituan. 16: 241-245.

GENOV T. 1984: [Helminths of insectivores and rodents in Bulgaria.] Izdatelstvo na Balgarskata akademiya na naukite, Sofia, 348 pp. (In Bulgarian.)

HAUKISALMI V. 1989: Intestinal helminth communities of Sorex shrews in Finland. Ann. Zool. Fenn. 26: 401-409.

KornienKo S.A., GulyaeV V.D., MelnikOVA Yu.A. 2006: [On the morphology and systematics of cestodes of the genus Neoskrjabinolepis Spassky, 1947 (Cyclophyllidea, Hymenolepididae).] Zool. Zh. 85: 134-145. (In Russian.)

Kornienko S.A., Gulyaev V.D., Melnikova Yu.A. 2007: [New species of cestodes of the genus Neoskrjabinolepis
Spassky, 1947 (Cyclophyllidea, Hymenolepididae) from shrews of Russia.] Zool. Zh. 86: 259-269. (In Russian.)

MerkusheVA I.V., BoBKOVA A.F. 1981: [Helminths of domesticated and wild animals in Belarus.] Nauka i tehnika, Minsk, 120 pp. (In Russian.)

SPASSKY A.A. 1947: [The phenomenon of confluence of proglottides and uteri in cestodes.] Dokl. AN SSSR 58: 723-724. (In Russian.)

SPASSKY A.A. 1954: [Classification of hymenolepidids of mammals.] Trudy GELAN 7: 120-167. (In Russian.)

SPASSKY A.A., ANDREYKO O.F. 1970: [Cestodes of Insectivora of Moldavia.] Parazity Zhivotnykh i Rastenii 5: 44-59. (In Russian.)

VAUCHER C. 1971: Les Cestodes parasites des Soricidae d'Europe. Etude anatomique, révision taxonomique et biologie. Rev. Suisse Zool. 78: 1-113.

Accepted 12 March 2008 